\title{
Gout is not associated with the risk of fracture: a meta-analysis
}

\author{
Fanxiao Liu', Jinlei Dong', Dongsheng Zhou', Qinglin Kang ${ }^{2}$ and Fei Xiong ${ }^{2^{*}}$ (D)
}

\begin{abstract}
Background: Numerous quantitatively based studies measuring the association between gout and the risk of fractures remain inconclusive. In order to determine whether gout could increase the risk of fractures, a meta-analysis was performed systematically.

Methods: Electronic databases, MEDLINE/PubMed, Embase, and Cochrane Library were systematically searched to identify studies evaluating the association of gout and the risk of fractures. No restrictions on language, publication date, or journal of publication were imposed. Meta-analysis was performed to pool the outcome estimates of interest such as fracture incidence, fracture risk, and fracture risk in different sites and at different time points in the follow-up period.
\end{abstract}

Results: Screening determined that seven studies involving a total of 684,964 participants (151,002 in the gout group and 533,962 in the control group) were deemed viable for inclusion in the meta-analysis. The results of the analysis showed that gout would not significantly have a relatively higher risk of any fracture $(\mathrm{RR}=1.11,95 \% \mathrm{Cl} 0.98-1.26)$. Subgroup analysis showed consistent results for sexuality (female: $R R=1.13,95 \% \mathrm{Cl} 0.93-1.37$; male: $R R=0.99,95 \%$ $\mathrm{Cl}$ 0.91-1.07) and several occurring sites (humerus, wrist, vertebra, hip, upper limbs, and lower limbs). Additionally, the results demonstrated that urate-lowering drugs prescribed early during disease had neither adverse nor beneficial effect on the long-term risk of fractures ( $R R=0.89,95 \% \mathrm{Cl} 0.76-1.05)$.

Conclusions: This meta-analysis confirmed that gout was not associated with an increased risk of fractures. Urate-lowering drugs prescribed early during the course of disease had neither adverse nor beneficial effect on the long-term risk of fractures.

Keywords: Gout, Meta-analysis, Fracture risk, Urate-lowering drugs

\section{Introduction}

Gout affected $2.4 \%$ of adults in the UK [1] and more than eight million Americans [2], which was one of the most common rheumatic diseases [3]. The growing recognition indicated that gout did not just occur in men, but also in women, and caused a substantial disease burden with the significantly higher cost, morbidities, and mortality [4-8]. Additionally, hyperuricemia, a characteristic in gout, was reported to be an independent risk factor for cardiovascular diseases, diabetes, and even death [9-12]. In recent decades, concern has mounted regarding the association between gout and bone health. It was generally believed that chronic inflammation had

\footnotetext{
* Correspondence: xiongfei188@hotmail.com

${ }^{2}$ Department of Orthopedic Surgery, Shanghai Jiao Tong University Affiliated

Sixth People's Hospital, Yishan Road 600, Shanghai 200233, China

Full list of author information is available at the end of the article
}

a negative effect on the bones due to the stimulation of the inflammatory cascade and production of proinflammatory cytokines, so gout, a type of inflammatory arthritis, has been hypothesized to be associated with a high risk of fractures [13, 14]. However, the increased serum level of uric acid (UA) in gout [15], which is the degradation production of purine compounds [16], made the relationship inconsistent. UA may affect bone health, including resorption and formation, through its two-way control of oxidative stress due to its antioxidant or prooxidant properties [17], and several prior studies on the association between hyperuricemia and bone mineral density (BMD) also demonstrated conflicting results [18-22]. Meanwhile, the urate-lowering therapy faced a dilemma when considering the relationship with fracture. Therefore, the indistinct interaction of these factors

(C) The Author(s). 2019 Open Access This article is distributed under the terms of the Creative Commons Attribution 4.0 International License (http://creativecommons.org/licenses/by/4.0/), which permits unrestricted use, distribution, and reproduction in any medium, provided you give appropriate credit to the original author(s) and the source, provide a link to the Creative Commons license, and indicate if changes were made. The Creative Commons Public Domain Dedication waiver (http://creativecommons.org/publicdomain/zero/1.0/) applies to the data made available in this article, unless otherwise stated. 
made it challenging to determine whether gout was protective or detrimental to bone health.

Numerous quantitatively based studies debating the association between gout and the risk of fractures remain inconclusive. Tzeng et al. [23] reported that gout history increased the fracture risk, which was consistent with the results of a Chinese adult-based research conducted by Wang et al. [24]. However, the relationship became variable when focus on different fracture sites in the study performed by Paik et al. [17], in which the risk of fractures raised in the hip but not in the wrist. Kim et al. [25] conducted a large-scale epidemiological study and demonstrated the neutral association between gout and bone health, and Sultan et al. [1] reported the similar results in a nationally representative cohort research. Additionally, a population-based study in Taiwan demonstrated a lower fracture risk among gout patients prescribed urate-lowering therapy [23], while a 9\% higher risk was found in a Denmark registry-based study [26]. Hence, it was difficult to clarify the associations of gout and its related treatment with the risk of fractures based on these published observational studies.

The aim of this study was to assess precisely the risk of fractures among patients with gout and estimate the potential effect of urate-lowering therapy on the risk. Furthermore, several subgroup analyses based on the gender, fracture sites, and etc. were performed to reveal more influencing factors.

\section{Materials and methods}

The checklist of the Preferred Reporting Items for Systematic Reviews and Meta-Analyses (PRISMA) statement was followed in the conduction of this investigation (Additional file 1). Electronic searches, reference lists screening, study selection, data extraction, assessment of the risk of bias, and pooling of outcome estimates were performed by two investigators (LFX and XF) independently. Any disagreement was resolved by consensus or judgment of an arbitrator (DJL). Informed consent or ethics approval was not needed because all required data were retrieved from published articles.

\section{Data sources and search strategy}

Three electronic databases including MEDLINE/PubMed, Embase, and Cochrane Library (from inception to Feb 1, 2019) were searched through an iterative process using a combination of keywords and mesh terms "gout," "arthritis," or "uric acid" AND "fracture," "bone fracture," or "broken bone." No restrictions on language, date, or journal of publication were imposed. Additionally, reference lists of related literature (reviews, meta-analyses, and included studies) about gout patients and associated fracture risk were carefully screened to retrieve additional eligible studies not identified by electronic database searching.

\section{Study screening and selection}

Studies were included in the qualitative analysis if they confirmed criteria listed as below: (1) participants, subjects with a primary diagnosis of gout; (2) control group, subjects with no gout; (3) incidence of fractures was assessed in the gout group and control group; and (4) randomized/quasi-randomized/cluster controlled clinical trials and retrospective/prospective cohort studies.

Exclusion criteria were (1) study protocols, letters, correspondence, and conference addresses; (2) experimental studies or animal studies; or (3) trials without sufficient data to obtain endpoint outcomes of interest.

\section{Data extraction}

Following information was collected from included articles: first author's family name, year of publication, study design, inclusion criteria of participants, source of data, number of participants in the gout group and the control group, demographic and clinical characteristics of participants (age, sex, and comorbidities), follow-up, evaluation endpoint outcomes of interest (any fracture, upper limb fracture, lower limb fracture), and the drugs of urate-lowering therapy. Risk ratios (RR) and its related 95\% confidence intervals (CIs) were directly extracted from original articles if provided or calculated from individual patients' data.

\section{Risk of bias}

Newcastle-Ottawa Scale (NOS) [27] was used to assess the risk of bias for the quality of non-randomized studies, in which each study will be assessed according to eight items belonging to three categories: (1) study groups selection, (2) comparability of groups, and (3) outcome of interest. One score was earned if a certain item was clearly provided in the original literature, and a study with a total of scores $>7$ was considered as a high-quality study.

\section{Statistical analysis}

Two researchers (LFX and FX) repeatedly performed the processes of study screening and selection, data extraction, quality assessment of included studies, and data analyses independently. Any contradictoriness was resolved by discussion or an arbitrator (DJL) when consensus cannot be reached. Informed consent and ethics approvals were not required because all relevant data were extracted from published articles.

Meta-analysis was implemented to conduct the quantitative analysis and produce forest plots using Stata 12.0 Version (StataCorp, College Station, TX, USA). Evaluation parameters of interest involved the pooled RR as well as related 95\% CIs was used to assess fracture risk between these two groups using random-effect models. Subgroup analyses were performed to explore the source of heterogeneity that was assessed using the $I^{2}$ (statistically 
significant when $I^{2}>50 \%$ ). Sensitivity analysis (conducted by omitting studies one by one) and publication bias (performed using Egger test) were implemented to evaluate the stability of results. A two-tailed $p$ value $<0.05$ indicated statistically significant.

\section{Results}

\section{Study inclusion and exclusion}

A total of 2645 records were screened in the electronic databases searching process with another eight additional studies retrieved from screening reference lists of related articles. After 326 studies excluded by duplicates, 2291 excluded by reading titles and abstracts, and 32 studies were downloaded and carefully checked by reading full texts. After careful reading, five articles [1, 17, 23-25] involving eight datasets were considered to be qualified for the quantitative analysis of the association of gout with the risk of fractures, and four articles [1, 23, $26,28]$ were considered to be qualified for the quantitative analysis of the association of urate-lowering with the risk of fractures. The inclusion processes and reasons for exclusion were depicted in Fig. 1.
Search results and included participants

All included articles were published during 2016-2018 in English. Sample sizes of these studies ranged from 2674 to 292,808 . With regard to the data source, all seven studies [1, 17, 23-26, 28] involved in the participants from the different data source. As for study type, five described retrospective cohort studies [1, 23-26] and two prospective cohort study [17, 28]. Kim et al. and Paik et al. $[17,25]$ presented data about the association between gout and fracture risk in two different cohorts based on the fracture localizations. Therefore, these data from the same articles were collected simultaneously and presented as two datasets based on sexuality. Eventually, this meta-analysis was established based on eight datasets. For the first analysis of gout with the risk of fractures, the baseline methodological and procedural characteristics of selected studies and demographic data of enrolled participants were listed in Tables 1 and 2. For the second analysis of the association of urate-lowering with the risk of fractures, Tables 3 and 4 show the baseline methodological and procedural characteristics of selected studies and demographic data of enrolled participants.

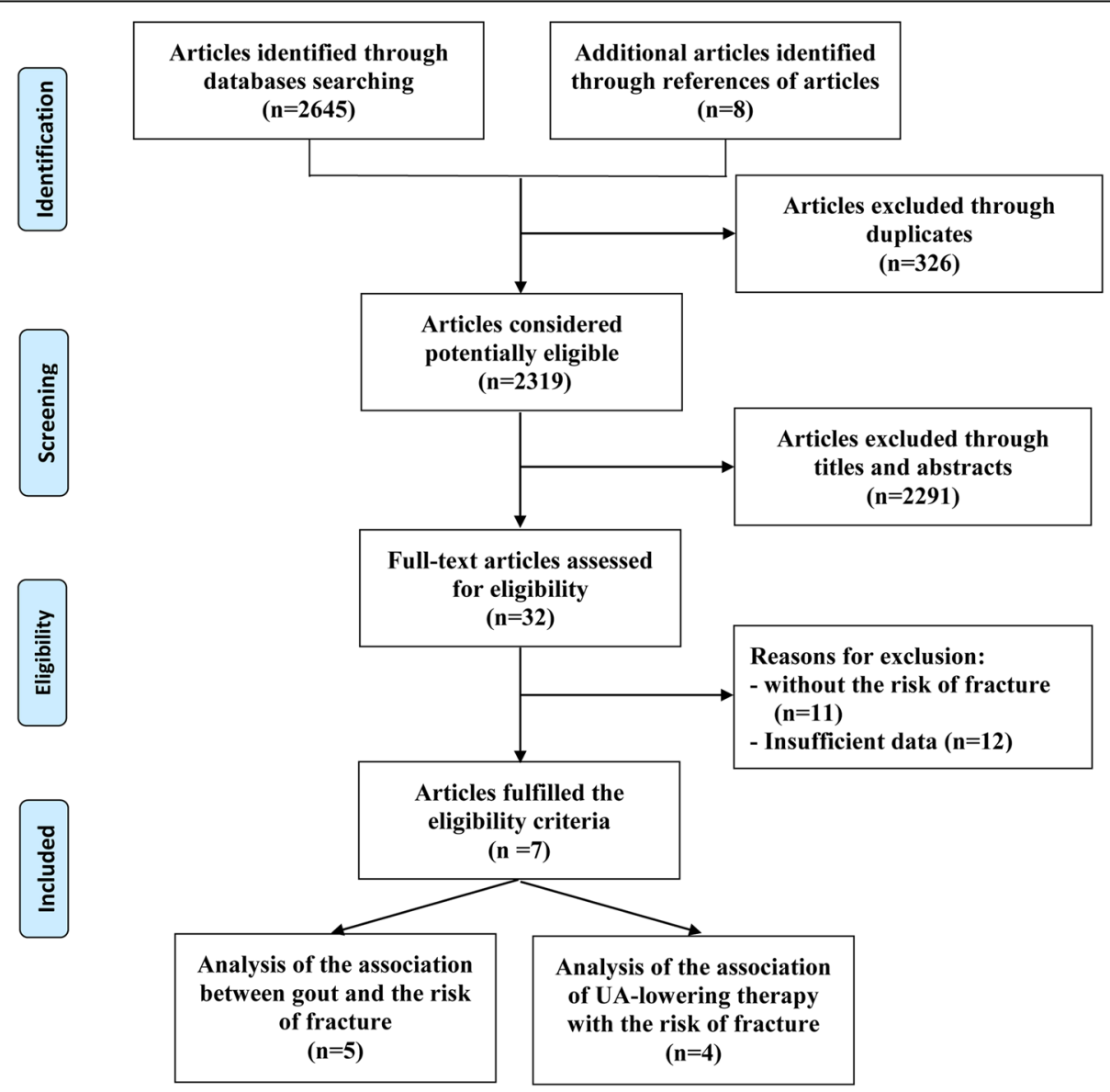

Fig. 1 PRISMA flow diagram of literature research and selection process 


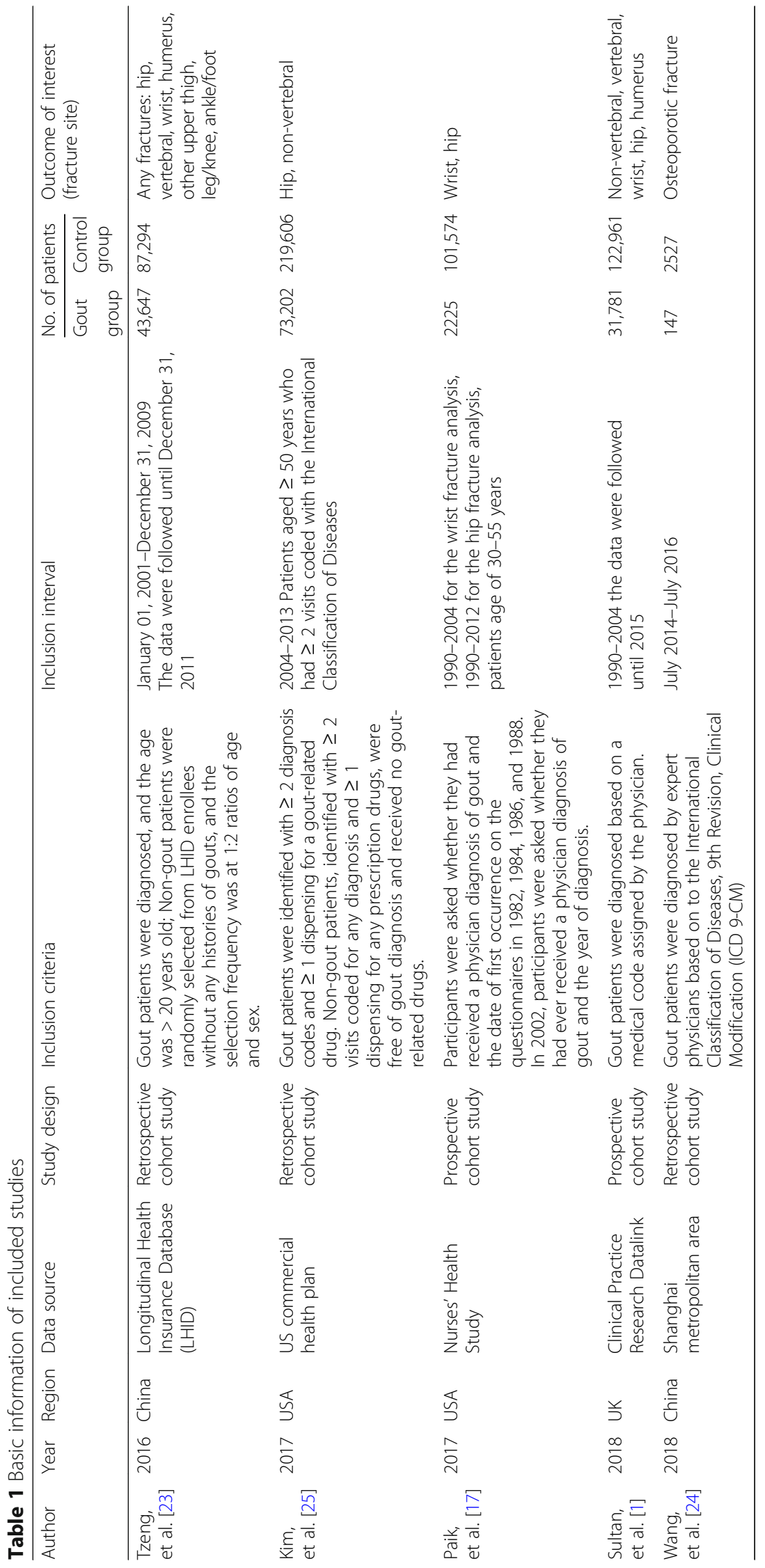


Table 2 Demographic characteristics of included participants

\begin{tabular}{|c|c|c|c|c|c|c|c|c|}
\hline \multirow[t]{2}{*}{ Author } & \multirow[t]{2}{*}{ Year } & \multicolumn{2}{|l|}{ Female, $n(\%)$} & \multicolumn{2}{|c|}{ Mean age, years } & \multicolumn{2}{|c|}{ Mean duration of follow-up, years } & \multirow[t]{2}{*}{ Comorbidities } \\
\hline & & Gout group & $\begin{array}{l}\text { Control } \\
\text { group }\end{array}$ & $\begin{array}{l}\text { Gout } \\
\text { group }\end{array}$ & $\begin{array}{l}\text { Control } \\
\text { group }\end{array}$ & Gout group & Control group & \\
\hline $\begin{array}{l}\text { Tzeng, } \\
\text { et al. [23] }\end{array}$ & 2016 & $13,142(30.1)$ & $\begin{array}{l}26,284 \\
(30.1)\end{array}$ & $50.9 \pm 16.0$ & $50.9 \pm 16.0$ & 11 & 11 & $\begin{array}{l}\text { ALD, CAD, COPD, DM, ESRD, hypertension, } \\
\text { osteoporosis, parkinson disease, stroke }\end{array}$ \\
\hline $\begin{array}{l}\text { Kim, } \\
\text { et al. [25] }\end{array}$ & 2017 & $13,176(18.0)$ & $\begin{array}{l}39,529 \\
(18.0)\end{array}$ & $60.0 \pm 7.5$ & $60.0 \pm 7.5$ & $2.0 \pm 1.7$ & $2.0 \pm 1.8$ & $\begin{array}{l}\text { Hypertension, stroke, cardiovascular disease, } \\
\text { bone mineral density testing ordered, } \\
\text { osteoporosis, dementia, chronic lung } \\
\text { disease, chronic kidney disease, CAD, } \\
\text { hyperlipidemia, obesity, DM, smoking, } \\
\text { alcoholism, comorbidity score }\end{array}$ \\
\hline $\begin{array}{l}\text { Paik, } \\
\text { et al. [17] }\end{array}$ & 2017 & $\begin{array}{l}2225 \\
(100)\end{array}$ & $\begin{array}{l}101,574 \\
(100)\end{array}$ & $59.6 \pm 6.5$ & $56.0 \pm 7.1$ & $\begin{array}{l}14 \text { for the wrist } \\
\text { fracture analysis; } \\
22 \text { for the hip } \\
\text { fracture analysis }\end{array}$ & $\begin{array}{l}14 \text { for the wrist } \\
\text { fracture analysis; } \\
22 \text { the hip fracture } \\
\text { analysis }\end{array}$ & $\begin{array}{l}\text { Current smokers, hypertension, DM, } \\
\text { osteoporosis, taking a thiazide diuretic }\end{array}$ \\
\hline $\begin{array}{l}\text { Sultan, } \\
\text { et al. [1] }\end{array}$ & 2018 & $\begin{array}{l}8601 \\
(17.1)\end{array}$ & $\begin{array}{l}32,983 \\
(16.8)\end{array}$ & $63.5 \pm 12.5$ & $63.1 \pm 12.2$ & $10.8(6.7-13.4)^{*}$ & $10.8(6.8-13.6)^{*}$ & $\begin{array}{l}\text { Smoking, alcohol consumption, history of } \\
\text { falls, antihypertensive agents, antidiabetic } \\
\text { agents, opioids, glucocorticoids, proton } \\
\text { pump inhibitors, selective serotonin reuptake } \\
\text { inhibitors, and bisphosphonates }\end{array}$ \\
\hline $\begin{array}{l}\text { Wang, } \\
\text { et al. [24] }\end{array}$ & 2018 & $\begin{array}{l}75 \\
(51.0)\end{array}$ & $\begin{array}{l}1646 \\
(65.1)\end{array}$ & $73.6 \pm 12.0$ & $75.6 \pm 12.3$ & Not mentioned & Not mentioned & $\begin{array}{l}\text { Rheumatic arthritis, CAD, hypertension, DM, } \\
\text { physical activity, alcohol, smoking }\end{array}$ \\
\hline
\end{tabular}

$A L D$ alcohol-related disorder, CAD coronary artery disease, COPD chronic obstructive pulmonary disease, DM diabetes mellitus, ESRD end-stage renal disease, *Median (IQR)

\section{Risk of bias}

As for the risk of bias of included articles, six studies [1, $17,23,25,26,28]$ were rated as low risks in all nine items while the study conducted by Wang et al. [24] failed to describe the outcome assessment, resulting deduction of one score. All included studies were rated as high quality in the risk of bias assessment (Additional file 2: Table S1).

\section{Meta-analysis of any fracture}

The combined results as generated from five studies [1, 17, 23-25] involving 151,002 patients in the gout group and 533,962 participants in the control group recorded the frequency of any fracture demonstrated that gout was not associated with the risk of any fracture (pooled $\mathrm{RR}=1.11$, 95\% CI 0.98-1.26, Fig. 2). Sensitivity analysis was conducted by omitting studies one by one (Additional file 2: Figure S1), subgroup analysis was implemented according to two factors including study design (retrospective or prospective) (Additional file 2: Figure S2), and the number of included patients ( $>$ or $<150$, 000 gout patients) (Additional file 2: Figure S3) revealed a consistent trend.

\section{Subgroup analysis based on sexuality}

The combined results as generated from four $[1,17,24$, $25]$ and three studies [1, 24, 25] recording the number of fractures occurring on female and male, demonstrated that compared with the control group, the pooled RR for any fracture were 1.13 (95\% CI 0.93-1.37) and 0.99 (95\%
CI 0.91-1.07) on female and male, indicated that sexuality had no effect on this association (Fig. 3).

\section{Subgroup analysis based on fracture sites}

The pooled results as generated from three $[1,17,23]$ and four studies [1, 17, 23, 25] recording the number of fractures occurring at the upper limb and lower limb, respectively, showed that gout would not increase the risk of the lower limb fracture (pooled $\mathrm{RR}=1.08,95 \% \mathrm{CI}$ 0.92-1.26) while showing a little increase in the risk of the upper limb fracture (pooled RR $=1.06$, 95\% CI 1.011.12) (Fig. 4). Further subgroup analyses were performed. There were two [1, 23], 3 [1, 17, 23], two [1, 23], two [1, 25], and four studies $[1,17,23,25]$ recording the number of fractures occurring at the humerus, wrist, vertebral and non-vertebral, and hip, respectively. The combined results showed that gout would not increase the risk of fractures (pooled $\mathrm{RR}=1.06,95 \% \mathrm{CI} 0.94-$ $1.19 ; \mathrm{RR}=1.07,95 \%$ CI $0.94-1.22 ; \mathrm{RR}=0.96,95 \% \mathrm{CI}$ $0.91-1.02 ; \mathrm{RR}=1.00,95 \%$ CI $0.84-1.18$ ) when compared with those in the control group (Fig. 5).

\section{Association of urate-lowering therapy with the risk of fractures}

The combined results as generated from four studies [1, $23,26,28]$ recorded the use of urate-lowering drugs demonstrated that urate-lowering drugs prescribed early during disease had neither adverse nor beneficial effect on the long-term risk of fractures (pooled $R R=0.89$, 95\% CI 0.76-1.05, Fig. 6). 


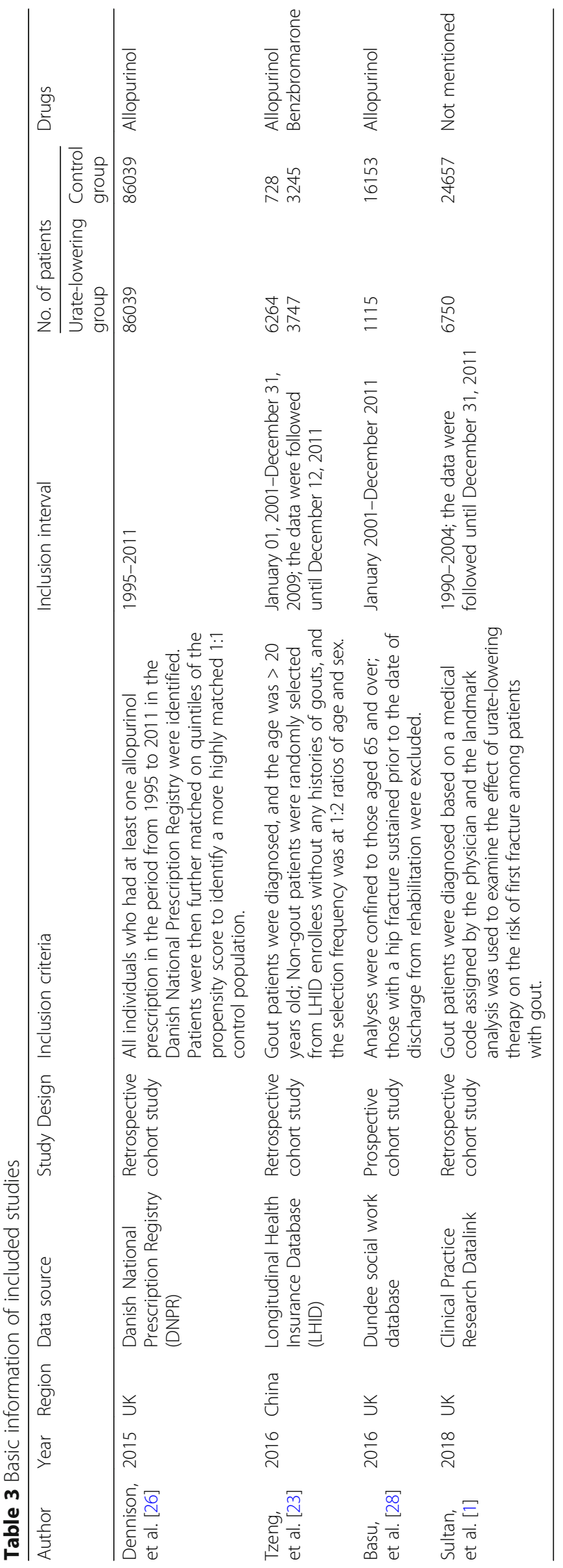


Table 4 Demographic characteristics of included participants

\begin{tabular}{|c|c|c|c|c|c|c|c|c|}
\hline \multirow[t]{2}{*}{ Author } & \multirow[t]{2}{*}{ Year } & \multicolumn{2}{|l|}{ Female, $n(\%)$} & \multicolumn{2}{|c|}{ Mean age, years (SD) } & \multicolumn{2}{|c|}{$\begin{array}{l}\text { Mean duration of } \\
\text { follow-up, years }\end{array}$} & \multirow[t]{2}{*}{ Comorbidities } \\
\hline & & $\begin{array}{l}\text { Urate-lowering } \\
\text { group }\end{array}$ & $\begin{array}{l}\text { Control } \\
\text { group }\end{array}$ & $\begin{array}{l}\text { Urate-lowering } \\
\text { group }\end{array}$ & $\begin{array}{l}\text { Control } \\
\text { group }\end{array}$ & $\begin{array}{l}\text { Urate-lowering } \\
\text { group }\end{array}$ & $\begin{array}{l}\text { Control } \\
\text { group }\end{array}$ & \\
\hline $\begin{array}{l}\text { Dennison, } \\
\text { et al. [26] }\end{array}$ & 2015 & $27,967(33)$ & $27,967(33)$ & $63(15.1)$ & $63(15.1)$ & 7 & 7 & $\begin{array}{l}\text { Allopurinol use, prior fracture, known } \\
\text { comorbidity, drug history }\end{array}$ \\
\hline $\begin{array}{l}\text { Tzeng, } \\
\text { et al. [23] }\end{array}$ & 2016 & $\begin{array}{l}\text { Not } \\
\text { mentioned }\end{array}$ & $\begin{array}{l}\text { Not } \\
\text { mentioned }\end{array}$ & $\begin{array}{l}\text { Not } \\
\text { mentioned }\end{array}$ & $\begin{array}{l}\text { Not } \\
\text { mentioned }\end{array}$ & 11 & 11 & $\begin{array}{l}\text { Age, sex, ALD, CAD, COPD, DM, ESRD, } \\
\text { hypertension, osteoporosis, Parkinson disease, } \\
\text { stroke, and each drug }\end{array}$ \\
\hline $\begin{array}{l}\text { Basu, } \\
\text { et al. [28] }\end{array}$ & 2016 & $487(43.7)$ & $9684(60.0)$ & $73.2(8.4)$ & $73.4(9.0)$ & 12 & 12 & $\begin{array}{l}\text { Age, sex, creatinine, albumin, hemoglobin, } \\
\text { diagnosis of diabetes mellitus, previous } \\
\text { admission with ischemic heart disease, stroke, } \\
\text { chronic heart failure, COPD, bisphosphonate } \\
\text { prescription, vitamin D and calcium prescription, } \\
\text { any exposure to allopurinol prior to the index } \\
\text { date, and provision of a package of social care }\end{array}$ \\
\hline $\begin{array}{l}\text { Sultan, } \\
\text { et al. [1] }\end{array}$ & 2018 & 1925 (28.5) & $6443(26.1)$ & $64.9(12.0)$ & $63.0(12.5)$ & 10.8 & 10.8 & $\begin{array}{l}\text { Age, alcohol consumption, smoking status, } \\
\text { BMl, Charlson index, opioids, fall, glucocorticoids, } \\
\text { nonsteroidal anti-inflammatory drugs, } \\
\text { acetylsalicylic acid, proton pump inhibitors, } \\
\text { antidiabetic and antihypertensive agents, and } \\
\text { selective serotonin reuptake inhibitors }\end{array}$ \\
\hline
\end{tabular}

$A L D$ alcohol-related disorder, CAD coronary artery disease, COPD chronic obstructive pulmonary disease, DM diabetes mellitus, ESRD end-stage renal disease

\section{Discussion}

This meta-analysis aimed to address the fracture risk of patients with gout and demonstrated that gout was not associated with an increased risk of fractures for any site, such as the humerus, wrist, vertebral, and hip fracture. In addition, urate-lowering drugs prescribed early during the course of disease had neither adverse nor beneficial effect on the long-term risk of fractures.

As a typical feature of gout, high UA levels were demonstrated an inconsistent relationship with BMD and fracture, because the diverse properties of UA depend on the specific conditions. The protective effects of UA

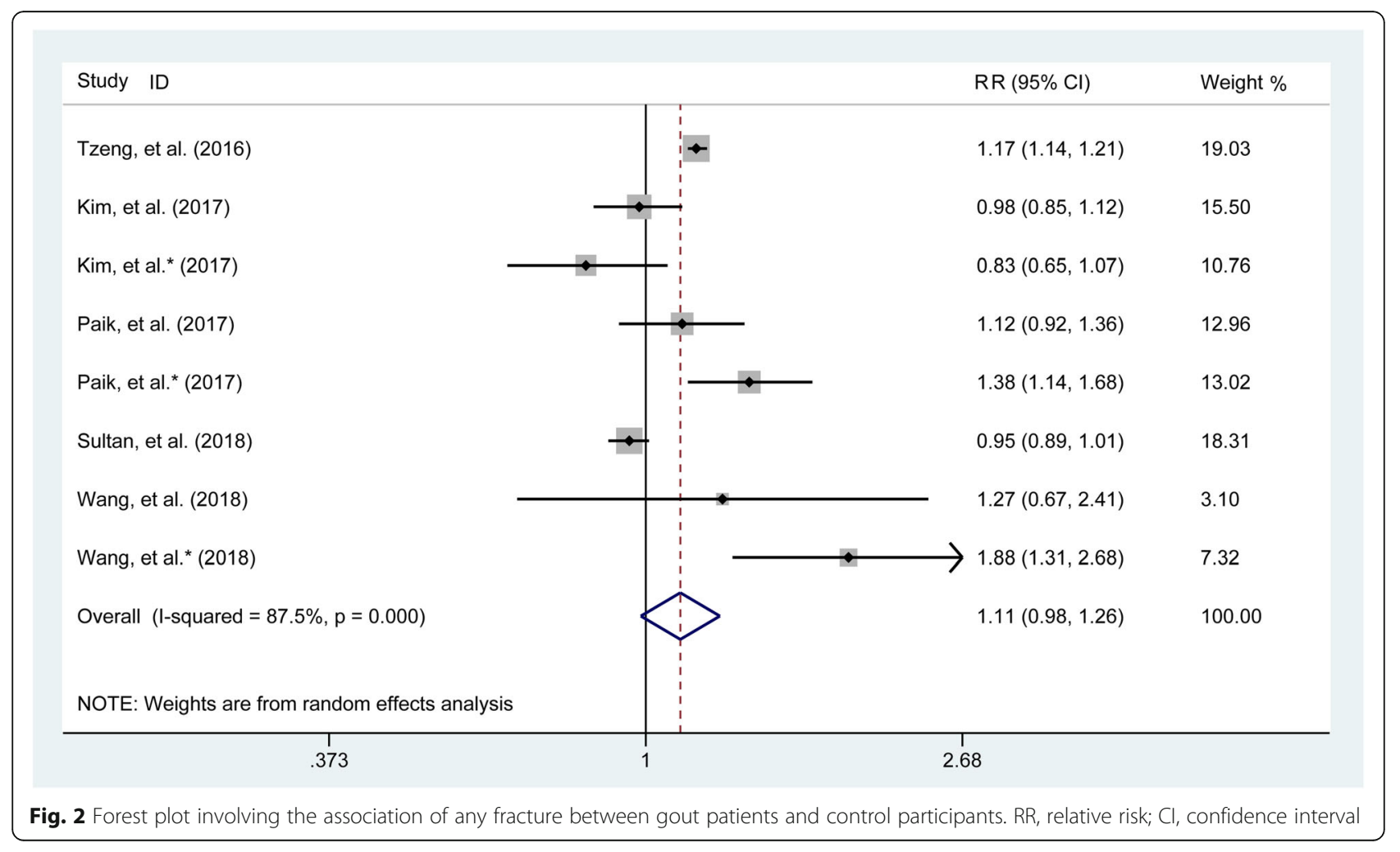




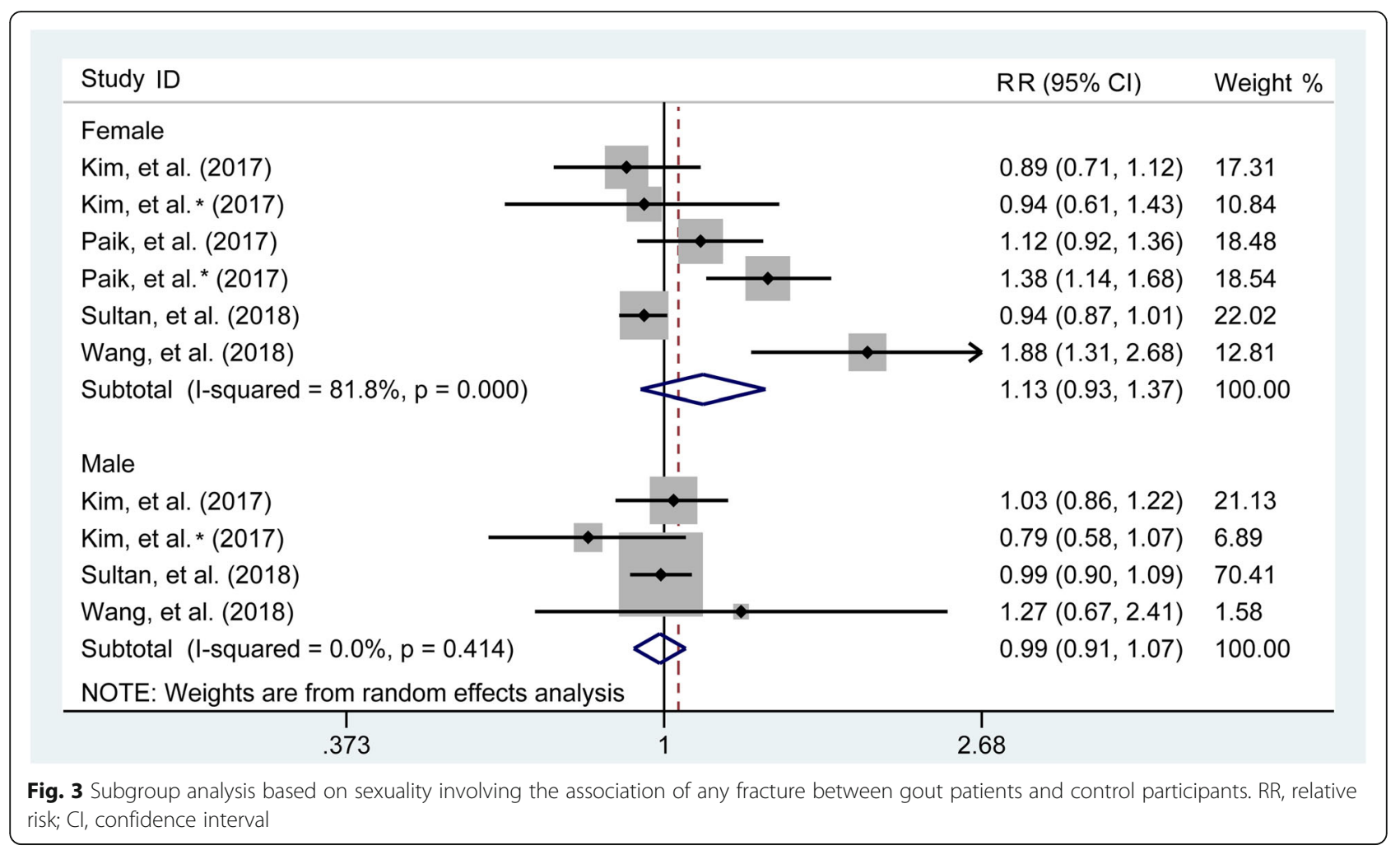

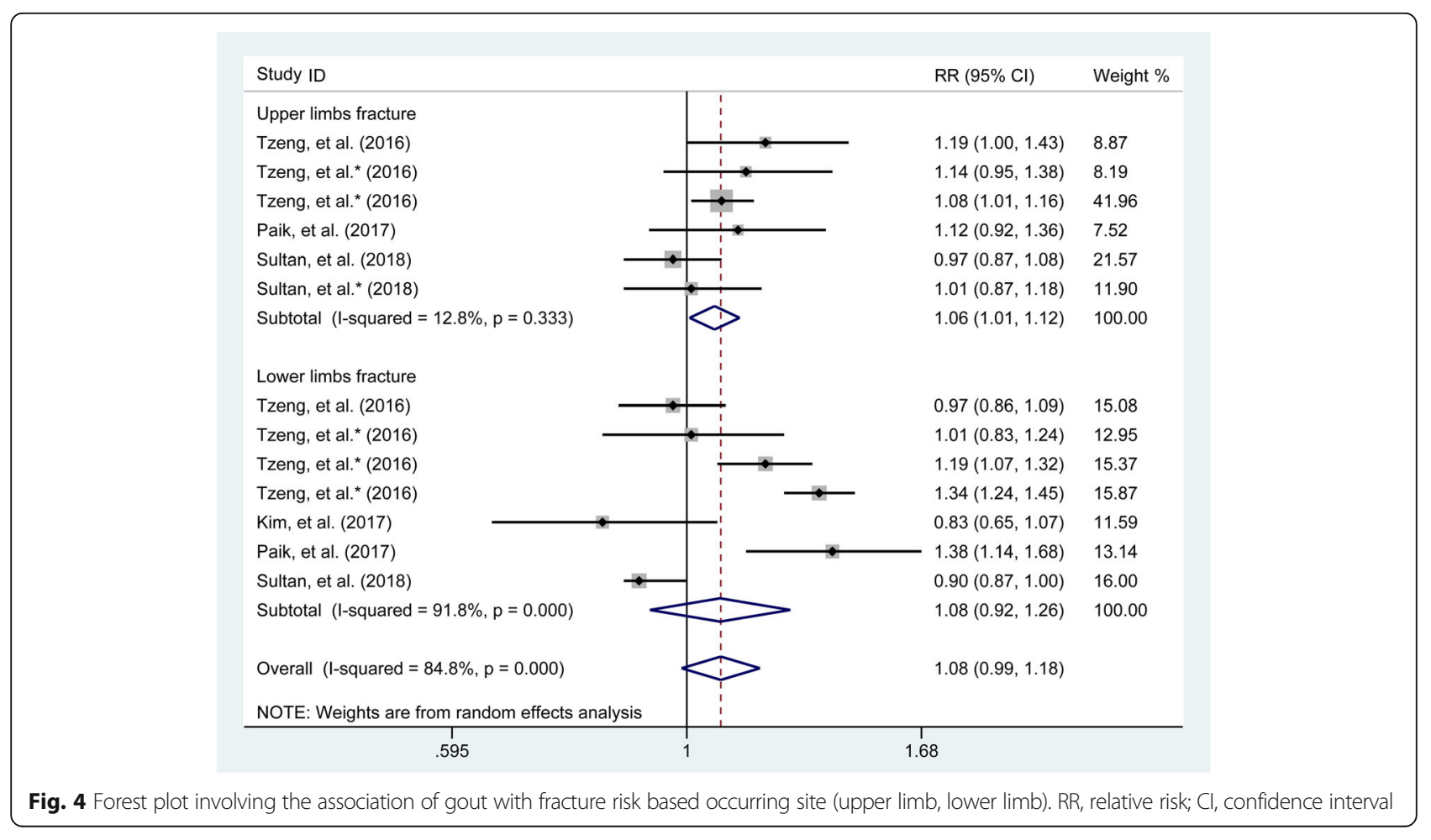




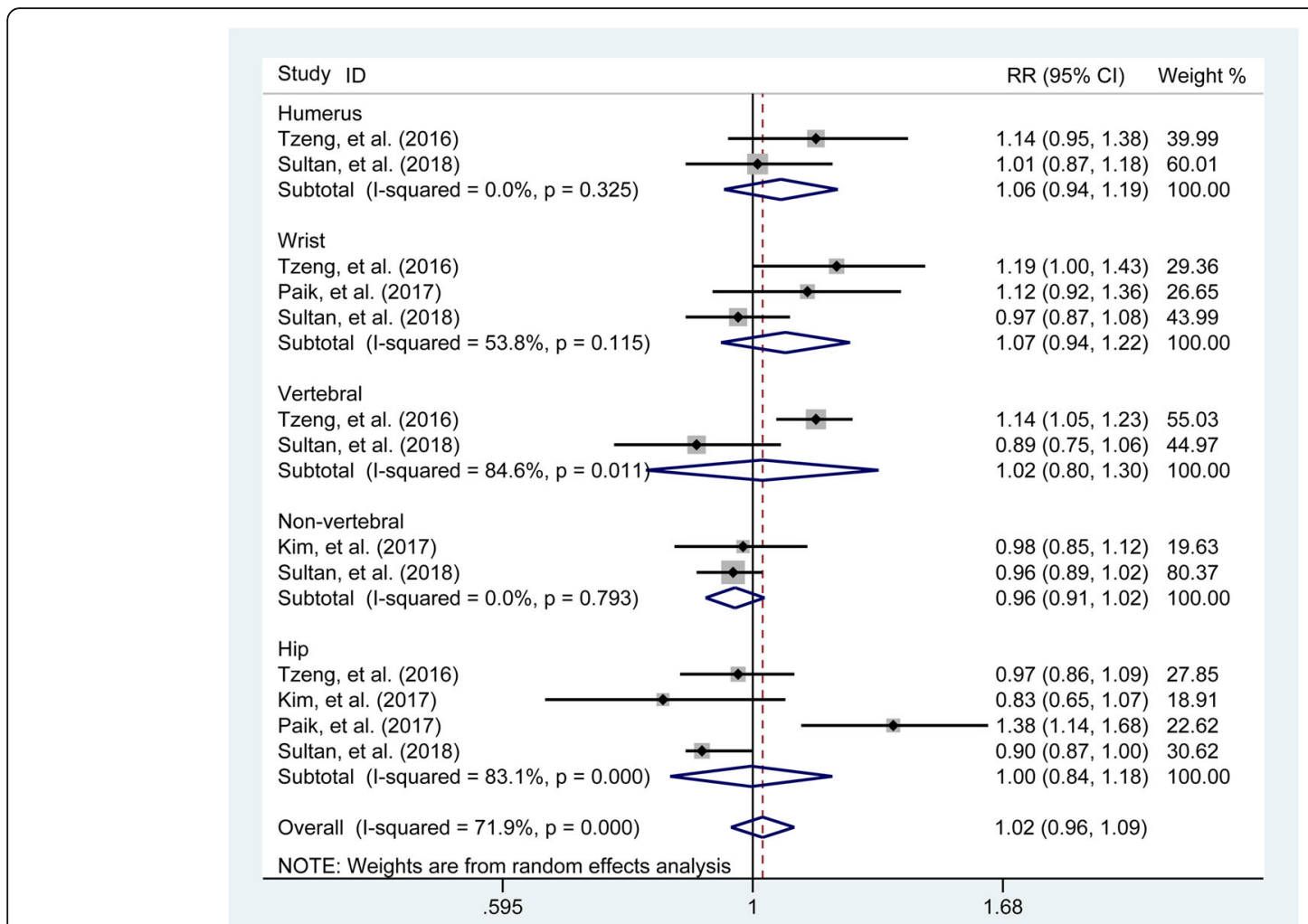

Fig. 5 Forest plot involving the association of gout with the fracture risk based occurring site (humerus, wrist, vertebral, non-vertebral or hip). RR, relative risk; $\mathrm{Cl}$, confidence interval

on BMD are mainly because of the antioxidant function or via vitamin $\mathrm{D} /$ parathyroid hormone pathway [29-31]. The pro-oxidant properties are dominant when UA exists at supersaturated concentrations, such as in gout, and results in oxidative stress [32, 33]. Numerous cross- sectional analyses demonstrated the positive or inverse association between UA and BMD [18-21]. The more recent one based on the National Health and Nutrition Examination Survey (NHANES) reported the neutral results which were also supported by animal data [22];

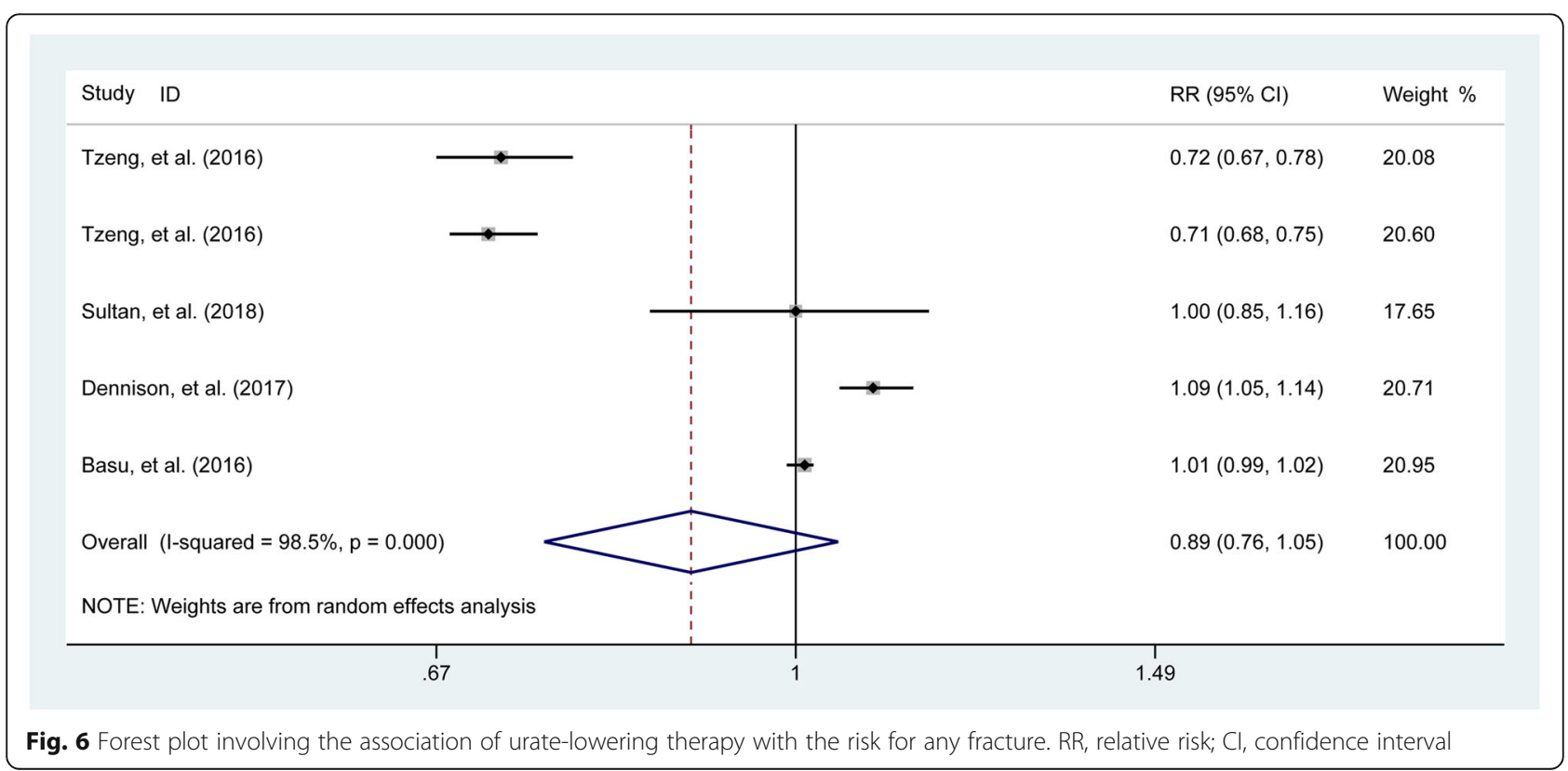


however, a prospective Rotterdam Study revealed that a higher UA level led to a higher BMD [34]. In terms of the association between UA and fracture risk, the results also remained inconsistent, which may be partly related to the age and sex distribution in different studies. A prospective Osteoporotic Fractures in Men (MrOS) study recruiting 5994 men aged 65 years or old showed a higher UA level had a negative impact on the risk of non-spine fracture, but not applied in hip fracture [35]. A more recent prospective study included 1963 men and 2729 women and found a significant positive association between high UA level and an increased risk of hip fractures, but only in men [36].

Hyperuricemia is a necessary but not sufficient predisposing factor for gout [23], which is also characterized by uric acid crystals and inflammatory. Importantly, the uric acid crystals can activate the NOD-like receptor protein-3 (NLRP3) [37, 38], which act as a diver of proinflammatory cytokines. Additionally, interleukin-1 beta (IL-1 $\beta)$, a strong stimulator of bone resorption, can be produced in the inflammatory cascades during gout [39-41]. These effects further promote osteoclastogenesis and osteoclast differentiation and may be related to the changes in BMD, thereby potentially increasing fracture risk [42-46]. Therefore, the complex pathophysiology made the relationship between gout and fracture varied.

Our research based on the analysis of seven studies including 151,002 gout patients and 533,962 participants in the control group revealed that there was no significant association between gout and fracture risk. Three of these articles demonstrated different conclusions from ours. Although Tzeng et al. [23] found that gout increased the overall fracture risks, the absent detailed information regarding important lifestyle-related factors (body mass index, smoking status, and alcohol habit) in the National Health Insurance research database (NHIRD) may confound their conclusions. The large prospective cohort study performed by Paik and colleagues showed that a history of gout modestly increased the risk of hip fracture in women but was not associated with wrist fracture [17]. However, the population in this study was female, so their findings should be carefully generalizable to men, while our subgroup analysis based on gender did not show significant a significant increase in the risk of fractures. Wang et al. [24] demonstrated that, in Chinese adults, gout significantly increased the risk of osteoporotic fractures in women. Because of its cross-sectional design, some biases were inherent, and the causal relationship between gout, fractures, and osteoporosis cannot be established; therefore, the results required cautious interpretation. Notably, a subgroup analysis based on the site of fractures was conducted in our research; the results showed that gout increased the risk of upper limb fractures, but a more detailed location analysis (humerus, wrist, and etc.) made the relationship disappear. Therefore, more prospective studies focusing on different factors should be performed to identify the association between gout and high fracture incidence under specific conditions.

We found that gout-related medication had a neutral effect on the risk of fractures, although previous literature on this topic was conflicting. Dennison et al. [26] reported that $9 \%$ excess risk of osteoporotic fractures was associated with gouty arthritis requiring allopurinol; however, the significant differences of characteristics between the exposed group and nonusers, and the control group involving non-gout participants may affect their observation. The opposite conclusion was raised by Tzeng et al. [23], in which urate-lowering therapy decreased a $28 \%$ risk of fractures among gout patients, while this study ignored the exclusion of the patients in the exposed group who underwent other events before the first prescription of urate-lowering therapy. A cohort study conducted by Sul$\tan$ et al. demonstrated that urate-lowering therapy had a neutral effect on the long-term risk of fractures [1]. Although the use of 1- and 3-year landmarks to some extent limited the generalization of the population, the nationally representative data recording enables us to understand better the causal relationship between therapy and fractures with minimum bias.

The strength of this study compared with previous investigations lies in the large quantity of included data, reliable statistical methods, and comprehensive evaluation indexes. This meta-analysis included eight datasets by exhaustive database searching and reference screening, among which there were seven datasets from national or regional register databases. The large participant base made the results of this study well represented. Moreover, outcomes of interests were compared using a pairwise meta-analysis method and analyzed from multi-dimension to fully elucidate the association between gout and the risk of fractures and discuss the underlying mechanism. Findings of this meta-analysis provide the currently most comprehensive evidence about this issue, which will help gout patients and their clinicians to determine whether or not to make an appropriate therapeutic regimen to propose the fracture. Hence, the conclusions based on these articles were not fairly reliable.

Nevertheless, this investigation was not without limitations. First, we only demonstrated an overall effect of gout on fracture but were not able to analyze the influence of some clinical and demographical factors (e.g., age and comorbidities). Second, there were only two prospective studies, and no randomized controlled trials were included. However, given the properties of gout and source of data, large scale RCT is currently inaccessible. Third, several studies did not present all characteristics of participants, and these missing data affect and weaken the strength of conclusions. 


\section{Conclusion}

This meta-analysis confirmed that gout was not associated with an increased risk of fractures. Urate-lowering drugs prescribed early during the course of disease had neither adverse nor beneficial effect on the long-term risk of fractures.

\section{Additional files}

Additional file 1: PRISMA checklist. The checklist of the Preferred Reporting Items for Systematic Reviews and Meta-Analyses (PRISMA). (DOC 64 kb)

Additional file 2: Supplementary figures 1-3 and table 1. (DOC 2252 kb)

\section{Abbreviations}

BMD: Bone mineral density; Cls: Confidence intervals; IL-1ß: Interleukin-1 beta; MrOS: Osteoporotic Fractures in Men; NHANES: National Health and Nutrition Examination Survey; NHIRD: National Health Insurance Research Database; NLRP3: NOD-like receptor protein-3; NOS: Newcastle-Ottawa Scale; PRISMA: Preferred Reporting Items for Systematic Reviews and Meta-Analyses; RR: Risk ratios; UA: Uric acid

\section{Acknowledgements}

Not applicable.

\section{Authors' contributions}

LFX, XF, and DJL conceived and designed the study. LFX, XF, and DJL performed the search, extraction of data, and methodological assessment. All authors analyzed the data and wrote the paper. All authors read and approved the final manuscript.

\section{Funding}

This study was supported by the National Natural Science Foundation of China (Jinlei Dong, No. 81301556) and China Scholarship Council (CSC) which funded two of the authors (Fanxiao Liu, NO. 201808080126; Fei Xiong, NO. 201706920036).

\section{Availability of data and materials}

All data generated or analyzed during this study are included in this published article.

\section{Ethics approval and consent to participate}

Not applicable.

\section{Consent for publication}

Not applicable.

\section{Competing interests}

The authors declare that they have no competing interests.

\section{Author details}

${ }^{1}$ Department of Orthopaedics, Shandong Provincial Hospital Affiliated to Shandong University, No.324, Road Jing Wu Wei Qi, Jinan 250021, Shandong, China. ${ }^{2}$ Department of Orthopedic Surgery, Shanghai Jiao Tong University Affiliated Sixth People's Hospital, Yishan Road 600, Shanghai 200233, China.

Received: 5 July 2019 Accepted: 15 August 2019

Published online: 27 August 2019

\section{References}

1. Sultan AA, Whittle R, Muller $S$, et al. Risk of fragility fracture among patients with gout and the effect of urate-lowering therapy. CMAJ. 2018;190(19): E581-7.

2. Hainer BL, Matheson E, Wilkes RT. Diagnosis, treatment, and prevention of gout. Am Fam Physician. 2014;90(12):831-6.

3. Chen JH, Yeh WT, Chuang SY, Wu YY, Pan WH. Gender-specific risk factors for incident gout: a prospective cohort study. Clin Rheumatol. 2012;31 (2):239-45.
4. Arromdee E, Michet CJ, Crowson CS, O'Fallon WM, Gabriel SE. Epidemiology of gout: is the incidence rising? J Rheumatol. 2002;29(11):2403-6.

5. Zhu Y, Pandya BJ, Choi HK. Prevalence of gout and hyperuricemia in the US general population: the National Health and Nutrition Examination Survey 2007-2008. Arthritis Rheum. 2011;63(10):3136-41.

6. Rai SK, Burns LC, De Vera MA, Haji A, Giustini D, Choi HK. The economic burden of gout: a systematic review. Semin Arthritis Rheum. 2015;45(1):75-80.

7. Kim SC, Liu J, Solomon DH. Risk of incident atrial fibrillation in gout: a cohort study. Ann Rheum Dis. 2016;75(8):1473-8.

8. Choi HK, Curhan G. Independent impact of gout on mortality and risk for coronary heart disease. Circulation. 2007;116(8):894-900.

9. Chen JH, Chuang SY, Chen HJ, Yeh WT, Pan WH. Serum uric acid level as an independent risk factor for all-cause, cardiovascular, and ischemic stroke mortality: a Chinese cohort study. Arthritis Rheum. 2009;61(2):225-32.

10. Kodama S, Saito K, Yachi Y, et al. Association between serum uric acid and development of type 2 diabetes. Diabetes Care. 2009;32(9):1737-42.

11. Ward HJ. Uric acid as an independent risk factor in the treatment of hypertension. Lancet. 1998;352(9129):670-1.

12. Holme I, Aastveit AH, Hammar N, Jungner I, Walldius G. Uric acid and risk of myocardial infarction, stroke and congestive heart failure in 417, 734 men and women in the Apolipoprotein MOrtality RISk study (AMORIS). J Intern Med. 2009;266(6):558-70.

13. van Staa TP, Geusens P, Bijlsma JW, Leufkens HG, Cooper C. Clinical assessment of the long-term risk of fracture in patients with rheumatoid arthritis. Arthritis Rheum. 2006:54(10):3104-3112.

14. Vosse D, Landewe R, van der Heijde D, van der Linden S, van Staa TP, Geusens P. Ankylosing spondylitis and the risk of fracture: results from a large primary care-based nested case-control study. Ann Rheum Dis. 2009;68(12):1839-42.

15. Pluta RM, Shmerling RH, Burke AE, Livingston EH. JAMA patient page. Gout. JAMA. 2012:308(20):2161.

16. Rott KT, Agudelo CA. Gout. JAMA. 2003;289(21):2857-60.

17. Paik JM, Kim SC, Feskanich D, Choi HK, Solomon DH, Curhan GC. Gout and risk of fracture in women: a prospective cohort study. Arthritis Rheumatol. 2017:69(2):422-8.

18. Makovey J, Macara M, Chen JS, et al. Serum uric acid plays a protective role for bone loss in peri- and postmenopausal women: a longitudinal study. Bone. 2013;52(1):400-6.

19. Ahn $\mathrm{SH}$, Lee $\mathrm{SH}$, Kim BJ, et al. Higher serum uric acid is associated with higher bone mass, lower bone turnover, and lower prevalence of vertebral fracture in healthy postmenopausal women. Osteoporos Int. 2013;24(12): 2961-70.

20. Ishii S, Miyao M, Mizuno Y, Tanaka-Ishikawa M, Akishita M, Ouchi Y Association between serum uric acid and lumbar spine bone mineral density in peri- and postmenopausal Japanese women. Osteoporos Int. 2014; 25(3):1099-105.

21. Sritara C, Ongphiphadhanakul B, Chailurkit L, Yamwong S, Ratanachaiwong W. Sritara P. Serum uric acid levels in relation to bone-related phenotypes in men and women. J Clin Densitom. 2013;16(3):336-40.

22. Zhang D, Bobulescu IA, Maalouf NM, et al. Relationship between serum uric acid and bone mineral density in the general population and in rats with experimental hyperuricemia. J Bone Miner Res. 2015;30(6):992-9.

23. Tzeng HE, Lin CC, Wang IK, Huang PH, Tsai CH. Gout increases risk of fracture: a nationwide population-based cohort study. Medicine (Baltimore). 2016;95(34):e4669.

24. Wang Y, Zhou R, Zhong W, Hu C, Lu S, Chai Y. Association of gout with osteoporotic fractures. Int Orthop. 2018;42(9):2041-7.

25. Kim SC, Paik JM, Liu J, Curhan GC, Solomon DH. Gout and the risk of nonvertebral fracture. J Bone Miner Res. 2017:32(2):230-6.

26. Dennison EM, Rubin KH, Schwarz P, et al. Is allopurinol use associated with an excess risk of osteoporotic fracture? A National Prescription Registry study. Arch Osteoporos. 2015;10:36.

27. Wells G, Shea B, O'Connell D, et al. The Newcastle-Ottawa Scale (NOS) for assessing the quality of nonrandomised studies in meta-analyses. http:/ wwwohrica/programs/clinical epidemiology/oxfordasp (Accesson July 2019). 20 tu13.

28. Basu U, Goodbrand J, McMurdo MET, et al. Association between allopurinol use and hip fracture in older patients. Bone. 2016:84:189-93.

29. Takahashi S, Yamamoto T, Moriwaki Y, Tsutsumi Z, Yamakita J, Higashino K. Decreased serum concentrations of 1, 25(OH)2-vitamin D3 in patients with gout. Metabolism. 1998;47(3):336-8.

30. Chen W, Roncal-Jimenez C, Lanaspa M, et al. Uric acid suppresses 1 alpha hydroxylase in vitro and in vivo. Metabolism. 2014;63(1):150-60. 
31. Hui JY, Choi JW, Mount DB, Zhu Y, Zhang Y, Choi HK. The independent association between parathyroid hormone levels and hyperuricemia: a national population study. Arthritis Res Ther. 2012;14(2):R56.

32. Lippi G, Montagnana M, Franchini M, Favaloro EJ, Targher G. The paradoxical relationship between serum uric acid and cardiovascular disease. Clin Chim Acta. 2008:392(1-2):1-7.

33. Hershfield MS, Roberts $\sqcup$ 2nd, Ganson NJ, et al. Treating gout with pegloticase, a PEGylated urate oxidase, provides insight into the importance of uric acid as an antioxidant in vivo. Proc Natl Acad Sci U S A. 2010;107(32):14351-6.

34. Muka T, de Jonge EA, Kiefte-de Jong JC, et al. The influence of serum uric acid on bone mineral density, hip geometry, and fracture risk: the Rotterdam study. J Clin Endocrinol Metab. 2016;101(3):1113-22.

35. Lane NE, Parimi N, Lui LY, et al. Association of serum uric acid and incident nonspine fractures in elderly men: the Osteoporotic Fractures in Men (MrOS) study. J Bone Miner Res. 2014:29(7):1701-7.

36. Mehta T, Buzkova P, Sarnak MJ, et al. Serum urate levels and the risk of hip fractures: data from the Cardiovascular Health Study. Metabolism. 2015;64(3): 438-46.

37. Martinon F, Petrilli V, Mayor A, Tardivel A, Tschopp J. Gout-associated uric acid crystals activate the NALP3 inflammasome. Nature. 2006;440(7081):237-41.

38. Ghaemi-Oskouie F, Shi Y. The role of uric acid as an endogenous danger signal in immunity and inflammation. Curr Rheumatol Rep. 2011;13(2):160-6.

39. Lorenzo J, Horowitz M, Choi Y. Osteoimmunology: interactions of the bone and immune system. Endocr Rev. 2008;29(4):403-40.

40. Garlanda C, Dinarello CA, Mantovani A. The interleukin-1 family: back to the future. Immunity. 2013;39(6):1003-18.

41. Dinarello CA. Overview of the interleukin-1 family of ligands and receptors. Semin Immunol. 2013;25(6):389-93.

42. Braun T, Schett G. Pathways for bone loss in inflammatory disease. Curr Osteoporos Rep. 2012;10(2):101-8.

43. Lee YM, Fujikado N, Manaka H, Yasuda H, Iwakura Y. IL-1 plays an important role in the bone metabolism under physiological conditions. Int Immunol. 2010;22(10):805-16.

44. Allaeys I, Marceau F, Poubelle PE. NLRP3 promotes autophagy of urate crystals phagocytized by human osteoblasts. Arthritis Res Ther. 2013;15(6):R176.

45. Nakamura I, Jimi E. Regulation of osteoclast differentiation and function by interleukin-1. Vitam Horm. 2006;74:357-70.

46. Corrado A, Neve A, Maruotti N, Cantatore FP. Bone effects of biologic drugs in rheumatoid arthritis. Clin Dev Immunol. 2013;2013:945945.

\section{Publisher's Note}

Springer Nature remains neutral with regard to jurisdictional claims in published maps and institutional affiliations.

Ready to submit your research? Choose BMC and benefit from:

- fast, convenient online submission

- thorough peer review by experienced researchers in your field

- rapid publication on acceptance

- support for research data, including large and complex data types

- gold Open Access which fosters wider collaboration and increased citations

- maximum visibility for your research: over $100 \mathrm{M}$ website views per year

At $\mathrm{BMC}$, research is always in progress.

Learn more biomedcentral.com/submissions 